\title{
Superior outcomes with Argatroban for heparin-induced thrombocytopenia: a Bayesian network meta-analysis
}

\author{
Giorgia Colarossi $^{1} \cdot$ Nicola Maffulli ${ }^{2,3,4} \cdot$ Andromahi Trivellas $^{5} \cdot$ Heike Schnöring ${ }^{1} \cdot$ Nima Hatam $^{1} \cdot$ Markus Tingart $^{6}$. \\ Filippo Migliorini ${ }^{6}[\mathbb{C}$
}

Received: 20 September 2020 / Accepted: 15 March 2021 / Published online: 28 March 2021

(c) The Author(s) 2021

\begin{abstract}
Background Argatroban, lepirudin, desirudin, bivalirudin, and danaparoid are commonly used to manage heparin-induced thrombocytopenia related complications. However, the most suitable drug for this condition still remains controversial. Aim of the review This Bayesian network meta-analysis study compared the most common anticoagulant drugs used in the management of heparin-induced thrombocytopenia. Method All clinical trials comparing two or more anticoagulant therapies for suspected or confirmed heparin-induced thrombocytopenia were considered for inclusion. Studies concerning the use of heparins or oral anticoagulants were not considered. Data concerning hospitalisation length, thromboembolic, major, and minor haemorrhagic events, and mortality rate were collected. The network analyses were made through the STATA routine for Bayesian hierarchical random-effects model analysis with standardised mean difference (SMD) and log odd ratio (LOR) effect measures. Results Data from a total of 4338 patients were analysed. The overall mean age was $62.31 \pm 6.6$ years old. Hospitalization length was considerably shorter in favour of the argatroban group (SMD: - 1.70). Argatroban evidenced the lowest rate of major (LOR: - 1.51) and minor (LOR: - 0.57) haemorrhagic events. Argatroban demonstrated the lowest rate of thromboembolic events (LOR: 0.62), and mortality rate (LOR: - 1.16). Conclusion Argatroban performed better overall for selected patients with HIT. Argatroban demonstrated the shortest hospitalization, and lowest rate of haemorrhages, thromboembolisms, and mortality compared to bivalirudin, lepirudin, desirudin, and danaparoid.
\end{abstract}

Keywords Anticoagulants $\cdot$ Bleeding $\cdot$ Heparin-induced thrombocytopenia $\cdot$ Mortality $\cdot$ Thromboembolism

Filippo Migliorini

migliorini.md@gmail.com

1 Department of Cardiac and Thoracic Surgery, University Clinic Aachen, RWTH Aachen University Clinic, Pauwelsstraße 30, Aachen 52074, Germany

2 Department of Medicine, Surgery and Dentistry, University of Salerno, Via S. Allende, 84081 Baronissi, SA, Italy

3 School of Pharmacy and Bioengineering, Keele University School of Medicine, Thornburrow Drive, Stoke on Trent, England

4 Barts and the London School of Medicine and Dentistry, Centre for Sports and Exercise Medicine, Mile End Hospital, Queen Mary University of London, 275 Bancroft Road, London E1 4DG, England

5 Department of Orthopaedics, David Geffen School of Medicine At UCLA, Los Angeles, CA, USA

6 Department of Orthopaedics and Trauma Surgery, University Clinic Aachen, RWTH Aachen University Clinic, Pauwelsstraße 30, 52074 Aachen, Germany

\section{Impacts on practice}

- In patients with heparin-induced thrombocytopenia, rapid discontinuation of heparin and transition to a different anticoagulant therapy are essential.

- Several drugs have been proposed for the management of heparin-induced thrombocytopenia; however, the most effective drug remains controversial.

- Anticoagulant therapy in patients with heparin-induced thrombocytopenia reduces thrombotic and hemorrhagic risks.

- While the most effective drug remains controversial, this meta-analysis suggest argatroban may be superior to the other used drugs for the management of heparin induced thrombocytopenia. 


\section{Introduction}

Heparin-induced thrombocytopenia (HIT) is an immunomediated disorder that occurs in up to $5 \%$ of patients receiving therapeutic doses of heparin $[1,2]$. In selected patients, heparin exposure induces the formation of IgG-PF4-heparin complex [3] which can promote platelet activation and aggregation [4]. Typically, HIT occurs within ten days after the start of heparin administration [1]. A second exposure to heparin before antibodies have disappeared can result in a rapid onset of HIT [5]. Of note, the incidence of HIT is higher in patients receiving unfractionated heparin than in those exposed to low molecular weight heparin [6]. Low molecular weight heparin induces a smaller complex with PF4 compared to unfractionated heparin [7]. HIT occurs mainly in surgical patients, especially after cardiac or orthopaedic surgery [8]. The diagnosis of HIT is both clinical and serological [9]. ELISA assay and serotonin release assay have high sensitivity but low specificity for HIT [9]. The diagnosis is confirmed by the presence of "HIT antibodies" and any of the following events: (1) unexplained fall in platelet count $(<30 \%$ to $<50 \%)$; (2) thrombosis; (3) skin lesions at the heparin injection site; (4) acute systemic (anaphylactic) reactions [10]. Up to $55 \%$ of patients present deep venous thrombosis, while arterial thromboembolisms are uncommon [11]. Cessation of heparin may not be sufficient to prevent thromboembolic complications; thus, anticoagulant therapy must be promptly initiated $[12,13]$. Argatroban and lepirudin are direct thrombin inhibitors (DTI) approved by the Food and Drug Administration (FDA) for the treatment of HIT [14]. Bivalirudin, desirudin, and danaparoid are also commonly used for the management of HIT. Bivalirudin is a synthetic analogue of hirudins indicated for patients with HIT undergoing percutaneous coronary interventions (PCI) $[15,16]$. Desirudin is another DTI, belonging to the hirudins family, which is commonly administered in major orthopaedic procedures [17-19]; although danaparoid is a low molecular heparinoid, it also has been commonly administered to prevent complications of HIT [20, 21].

\section{Aim of the review}

Several studies compared the effectiveness of different parenteral anticoagulants for HIT, but the most effective drug for HIT remains controversial [22-40]. The present study compared the most common anticoagulant drugs used for the management of HIT. Therefore, a Bayesian network meta-analysis was conducted. The outcomes of interest of this study were hospitalization length, mortality, haemorrhagic, and thromboembolic rates.

\section{Method}

\section{Search strategy}

This Bayesian network meta-analysis was conducted according to the PRISMA extension statement for reporting of systematic reviews incorporating network meta-analyses of health care interventions [41]. The PICO protocol guided the initial search:

- P (Population): HIT;

- I (Intervention): parenteral anticoagulant therapies;

- C (Comparison): argatroban, bivalirudin, lepirudin, desirudin, danaparoid;

- (Outcomes): hospitalization length, haemorrhages, thromboembolism, mortality.

\section{Literature search}

Two independent reviewers (GC; FM) performed the literature search in February of 2021. The following online databases were accessed: Pubmed, EMBASE, Google Scholar, Scopus. The following keywords were used in combination: HIT, heparin, induced, thrombocytopenia, thromboembolism, deep vein thrombosis, bleeding, haemorrhagic, anticoagulants, argatroban, bivalirudin, lepirudin, desirudin, danaparoid, hospitalization length, platelet, haemoglobin, haematocrit, blood, thromboembolism, death, survivorship, therapy, treatment, thrombin, thrombin inhibitor, thrombosis prophylaxis, PF4, PF4 antibodies. The resulting articles were screened for inclusion. If the title and abstract matched the topic, the full text article was accessed. The bibliographies of the included studies were also screened for inclusion.

\section{Eligibility criteria}

All clinical trials investigating parenteral anticoagulant therapies for suspected or proven HIT were considered for inclusion. Studies in English, Italian, German, French, and Spanish, according to the authors language capabilities, were included. Studies of level of evidence I to III, according to the Oxford Centre of Evidenced-Based Medicine [42], were considered. Reviews, comments, editorials, opinions, reports, and data from registries were not considered. Animal and cadaveric studies were not included. Studies using other drugs rather than parenteral anticoagulants were not included. Trials comparing anticoagulants with heparin were not included, nor were studies that evaluated the 
effectiveness of these compounds in other thrombocytopenia conditions (e.g. neoplastic, idiopathic, haemolytic). Articles performing studies on oral anticoagulants (e.g. vitamin K antagonists, direct oral anticoagulants) were not included. Only clinical trials reporting quantitative data under the outcomes of interest were considered for inclusion. Disagreements between the reviewers were debated and solved by a third author $(\mathrm{SH})$.

\section{Outcomes of interest}

Data extraction was performed by two independent reviewers (GC, FM). Generalities of the studies were collected (author and year, journal, study design, eligibility criteria). Patient baseline was extracted, along with the name, dose, therapeutic and maintenance doses for each drug. The length of hospitalization was retrieved. Data on the rate of major and minor haemorrhagic events, thromboembolic complications, and mortality were collected.

\section{Methodological quality assessment}

The methodological quality assessment was performed by one reviewer (GC). For this purpose, the bias summary tool of the Review Manager Software (The Nordic Cochrane Collaboration, Copenhagen) was used. The following biases were analysed: selection, detection, attrition, reporting, and other sources of bias.

\section{Statistical analysis}

The statistical analyses were performed by the senior author (FM). For baseline comparability, the IBM SPSS software was used. Comparability was assessed through the Analysis of Variance (ANOVA), with $P>0.1$ considered satisfactory. The network analyses were made through the STATA/MP software (Stata Corporation, College Station, Texas, USA). The analyses were performed through the Stata routine for Bayesian hierarchical random-effects model analysis. Continuous variables were analysed through the inverse variance method, with the standardized mean difference (SMD) effect measure. Binary data was analysed through the Mantel-Haenszel method, with the Log Odd Ratio (LOR) effect measure. Edge, interval, and funnel plots were performed and analysed. The overall transitivity, consistency, and heterogeneity, as well as the size of the treatment effect of interest within-study variance, were evaluated. The overall inconsistency was evaluated through the equation for global linearity via the Wald test. If $\mathrm{P}_{\text {Wald }}$ values $>0.05$, the null hypothesis could not be rejected, and the consistency assumption could be accepted at the overall level of each treatment. Confidence and percentile intervals (CI, PrI, respectively) were each set at $95 \%$.

\section{Results}

\section{Search result}

The literature search resulted in 836 articles. Of them, 252 were duplicates. An additional 530 articles were excluded: nature of the study $(\mathrm{N}=207)$, non-clinical studies $(\mathrm{N}=153)$, use of other anticoagulants $(\mathrm{N}=84)$, use of adjuvant(s) $(\mathrm{N}=72)$, language limitations $(\mathrm{N}=12)$, uncertain results $(\mathrm{N}=2)$. Another 21 articles were rejected as quantitative data under the outcomes of interests were missing. Ultimately, 33 articles were included: 4 randomized clinical trials, 16 prospective, and 13 retrospective clinical studies (Fig. 1).

\section{Methodological quality assessment}

The Cochrane bias of summary tool evidenced some limitations of the present study. First, the overall retrospective nature of the included studies, along with the overall lacking of blinding methods led to increased selection and detection biases. Indeed, only 12\% (4 or 33 studies) were RCTs, and only two of these were blinded. The overall risks of attrition, reporting, and unknown sources of bias were acceptable. In conclusion, the risk of bias of the present work was fair-moderate. The Cochrane bias of summary tool is shown in Fig. 2.

\section{Patient demographics}

Data from 4338 patients were retrieved. A total of 1846 patients were analysed in the argatroban group, 318 in the bilivarudin group, 973 in the lepidurin group, 68 in the desirudin group, and 126 in the danaparoid group. 53.92\% (2339 of 4338 patients) were men. The overall mean age was $62.31 \pm 6.6$ years old. The ANOVA test found good comparability concerning age $(\mathrm{P}=0.07)$. The generalities and demographics of the included studies are shown in Table 1.

\section{Outcomes of interest}

Hospitalization length was shorter in the argatroban group (SMD: -1.70 ; 95\% CI: -67.93 to 64.53; Fig. 3).

Argatroban demonstrated the lowest rate of major (LOR: -1.51 ; $95 \%$ CI: -3.15 to 0.12 ; Fig. 4 ) and minor (LOR: -0.57 ; $95 \%$ CI: -3.30 to 2.15 ; Fig. 4) haemorrhagic events.

Argatroban demonstrated the lowest rate of thromboembolic events (LOR: 0.62 ; 95\% CI: -0.89 to 2.13 ; Fig. 5) and mortality rate (LOR: -1.16 ; $95 \%$ CI: -2.12 to -0.20 ; Fig. 6). 
Fig. 1 Flow-chart of the literature search

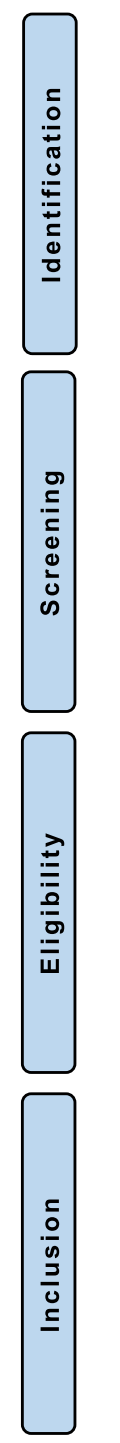

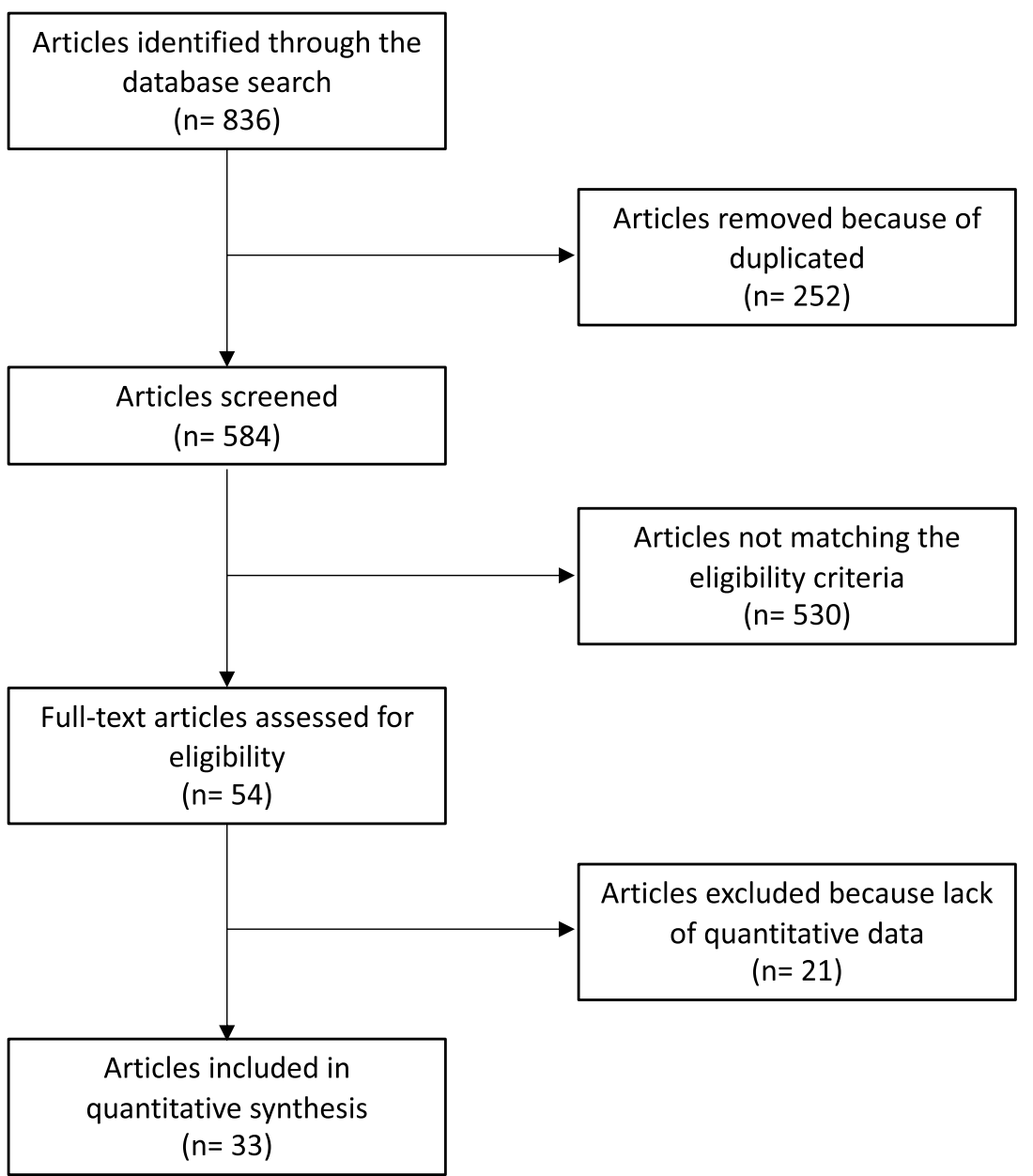

The equation for global linearity found no evidence of inconsistency among the comparisons: hospitalization $(P=0.3)$, major $(P=0.2)$ and minor $(P=0.4)$ haemorrhagic events, thromboembolism $(P=0.3)$, mortality rate $(P=0.2)$.

\section{Discussion}

According to the main findings of this Bayesian network meta-analysis, argatroban performed better than bivalirudin, lepirudin, desirudin, danaparoid for selected patients with HIT. Argatroban demonstrated the lowest rate of haemorrhages, thromboembolisms, and mortality, along with the shortest length of the hospitalization, compared to the other drugs of interest.

HIT is an immune mediated reaction triggered by the exposure to unfractionated heparin or low molecular weight heparin. Clinical manifestation is typically seen in 5 to 10 days after the start of heparin therapy [5, 43]. The most severe complications of HIT are thromboembolic events, and several studies have reported that heparin cessation may not be enough to prevent thrombosis: another anticoagulation method is recommended [44, 45]. Hirsh et al. [4] investigated the treatment of HIT with argatroban, lepirudin, and danaparoid. Despite the use of another anticoagulation method, the mortality in HIT is up to $22 \%$, while the risk of a new thromboembolic event is up to $18 \%$. In the present study, the efficacy and safety of five different anticoagulants were analysed: four belonging to the DTI family (argatroban, lepirudin, desirudin, bivalirudin) and one low molecular weight heparinoid (danaparoid). Argatroban is a univalent DTI that binds thrombin, inhibiting its action. Its good tolerability and short half-life make argatroban an attractive option for the management of HIT complications [46]. However, given its hepatic metabolism, argatroban is 


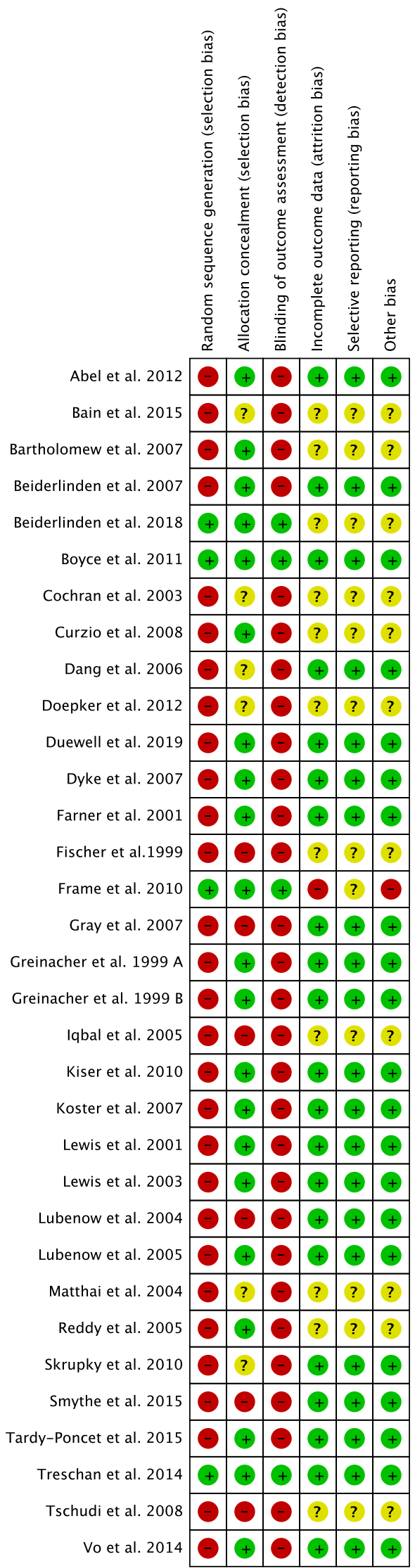

not recommended for patients with hepatic dysfunction [47], unless meticulous dose adjustments and aPTT monitoring are undertaken [44]. Conversely, danaparoid has longer halflife than argatroban, and good efficacy in maintaining stable anticoagulation [48]. Moreover, despite danaparoid being a low-molecular-weight heparinoid, its cross-reactivity with HIT antibodies is rare [48]. Hirudins (lepirudin, desirudin) are bivalent DTI, that bind with a high affinity and specificity to two distinct sites of thrombin [49]. However, give its renal metabolism, lepirudin must be administered with caution in nephropathic patients. Furthermore, immunogenicity has been associated with lepirudin consumption [50, 51]. In a meta-analysis by Greinacher et al. [43], lepirudin demonstrated lower mortality rate and thromboembolic events compared to the control group. Treschan et al. [52] compared argatroban versus lepirudin on 28 patients requiring renal replacement therapy. Patients randomized to lepirudin experienced a greater incidence of haemorrhagic complications [52]. These results were confirmed by the present study, which found a greater rate of haemorrhagic events following administration of lepirudin compared to argatroban and danaparoid. In a retrospective analysis comparing danaparoid (126 patients) versus lepirudin (175 patients) [53], interestingly, danaparoid was associated with a greater risk of new thromboembolic events in patients without thrombosis on admission. Although bivalirudin is mainly metabolized in the liver, nephropathic patients require dose adjustment [38, 54, 55]. Bivalirudin and argatroban were compared in a retrospective study which found that both anticoagulants reached the aPTT goal within six hours, and evidenced similarity between the two compounds [37]. Lastly, a meta-analysis, demonstrated similar efficacy and safety between argatroban, lepirudin, and bivalirudin [56].

This network meta-analysis has certain limitations. The retrospective nature of most of the included studies increased the risk of selection bias, reducing the reliability of the conclusions of the present study. The current literature lacks high-quality studies; therefore, additional studies should tackle this limitation. Furthermore, the low number of included studies and related patients represents another limitation. The presence of HIT-related complications on admission were not analysed in the present study, along with patient comorbidities (e.g. patients with liver and/or renal dysfunctions). Given the lack of quantitative data, a subgroup analysis according to the initial and maintenance doses could not be performed. Parenteral anticoagulants are frequently chosen for the management of HIT $[22,57]$.

Fig. 2 Methodological quality assessment 


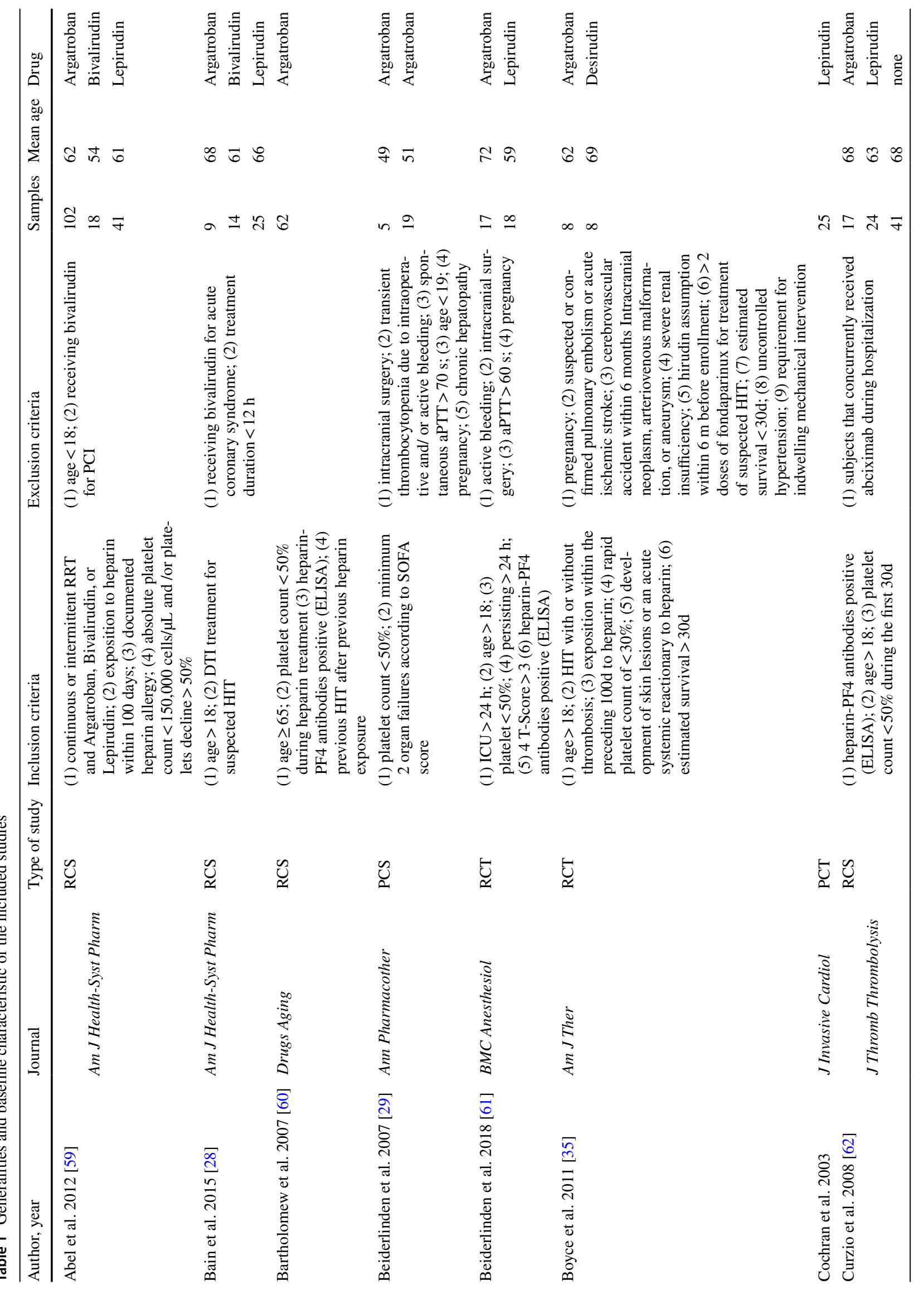




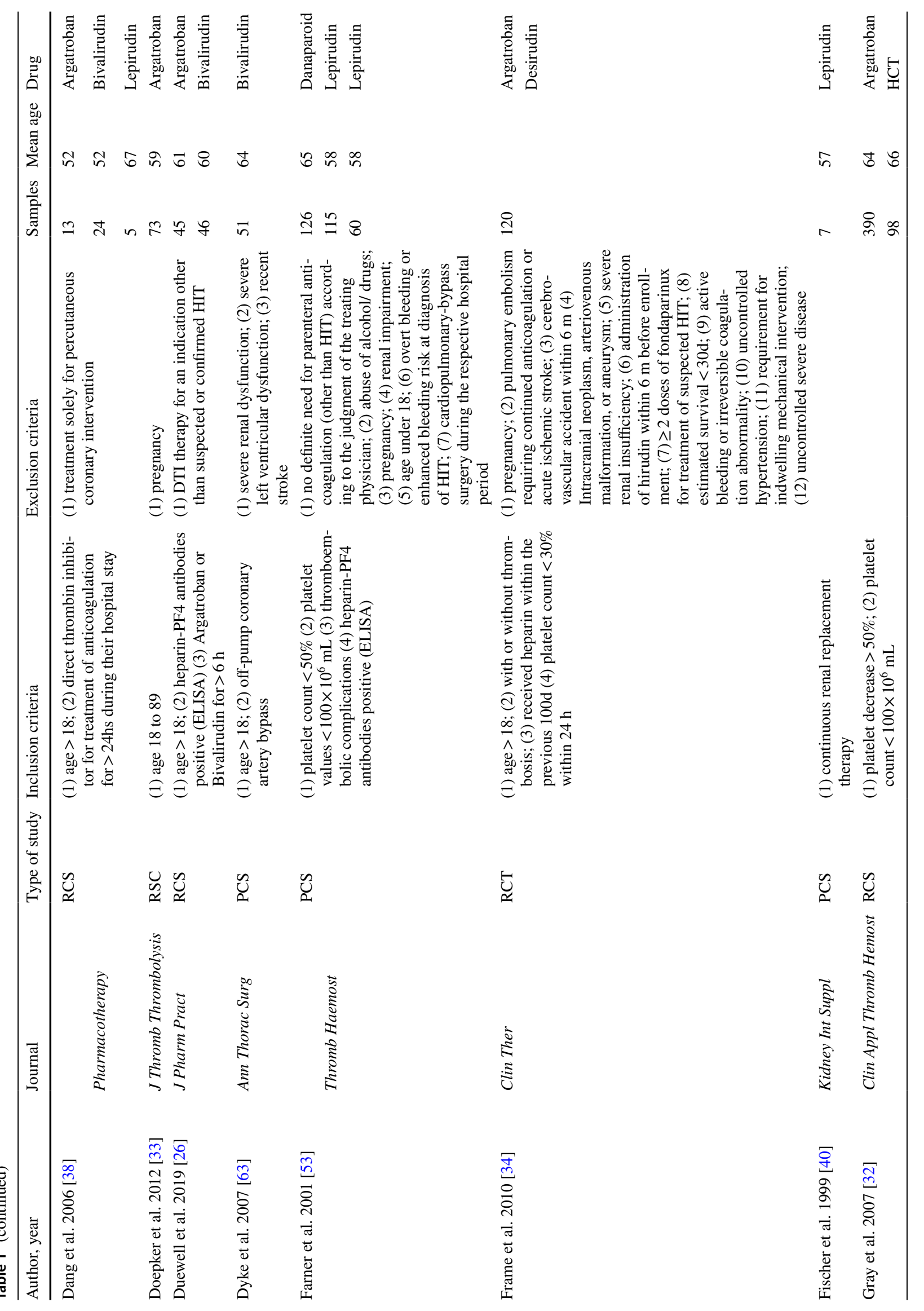




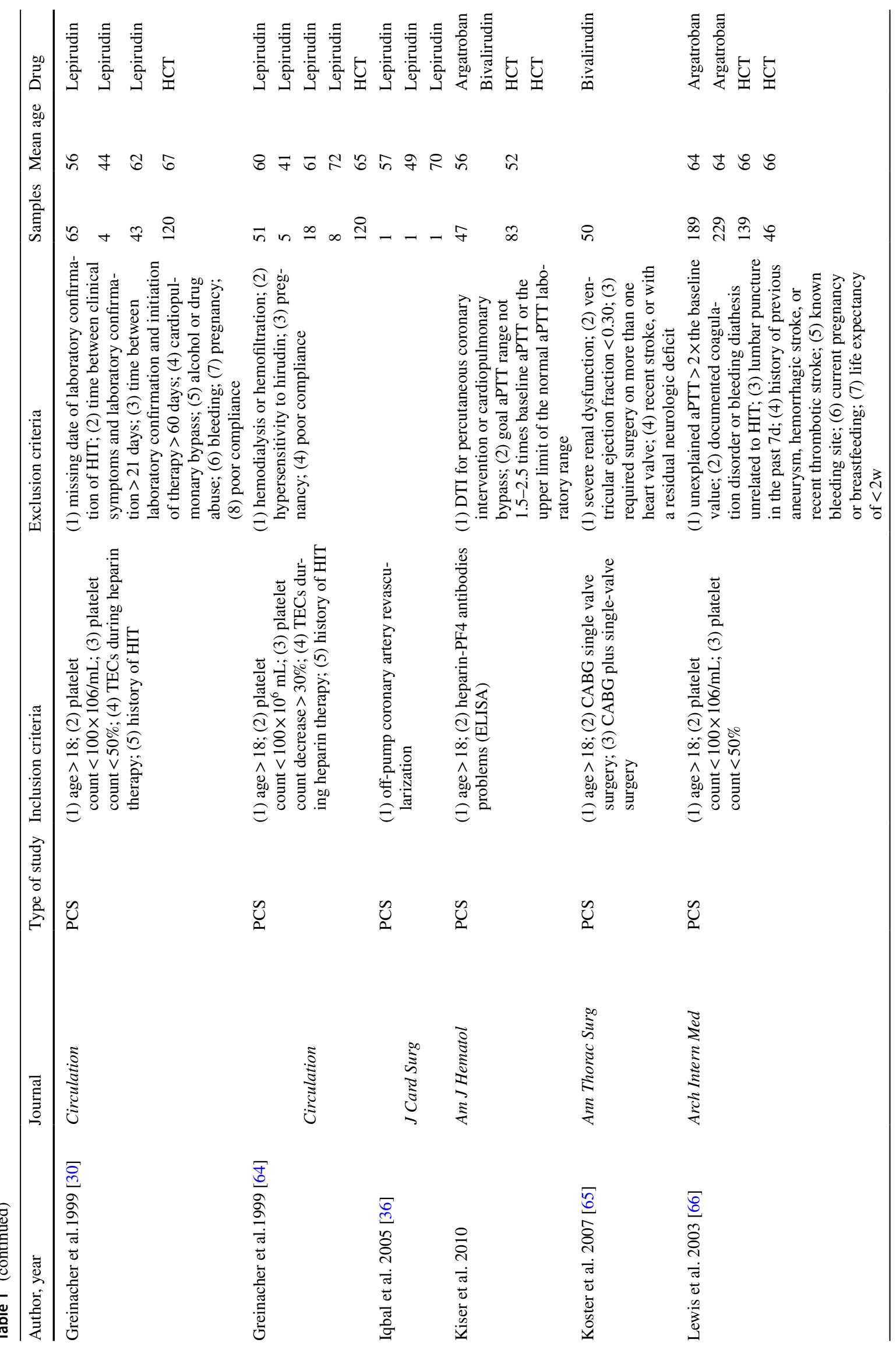




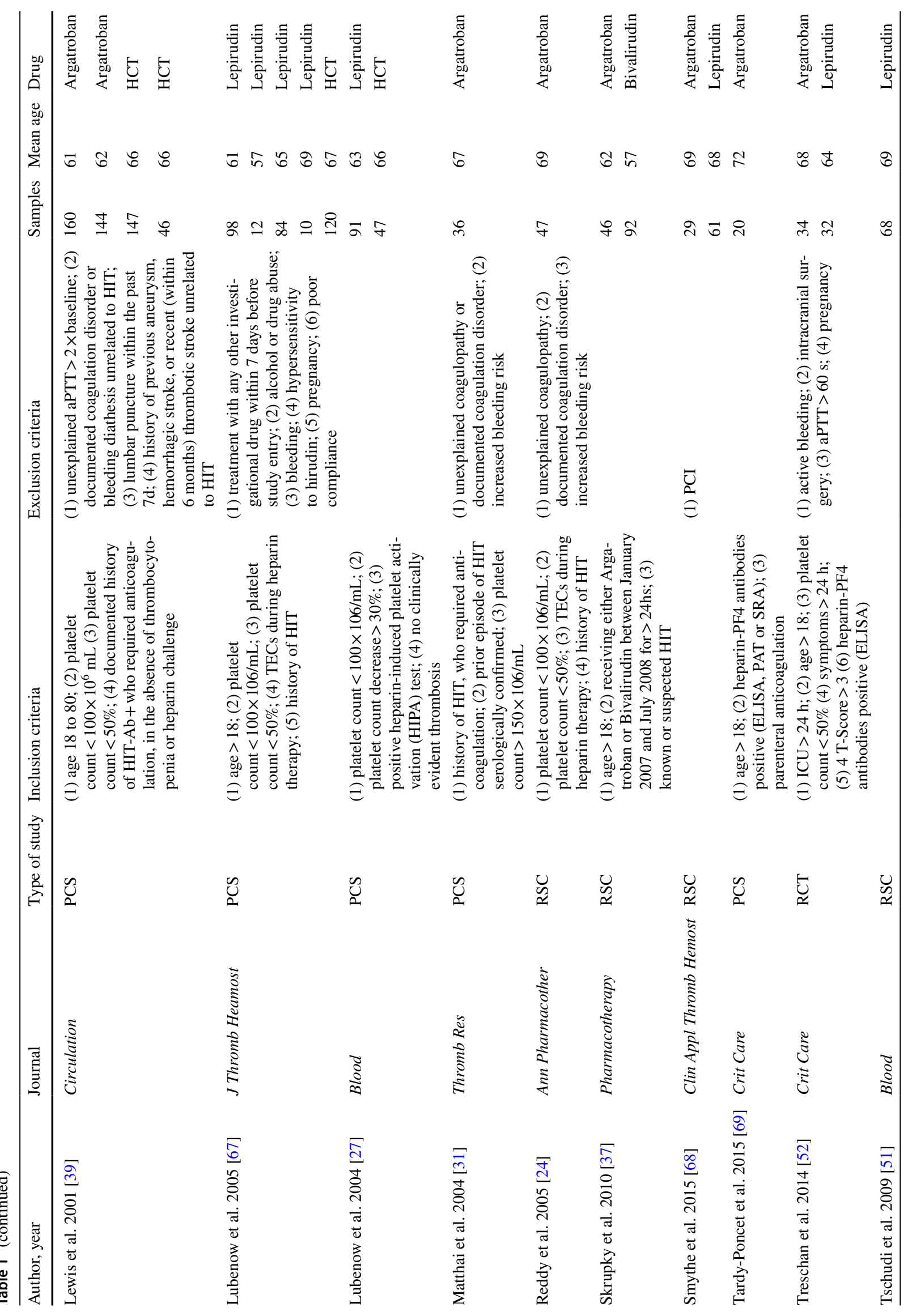




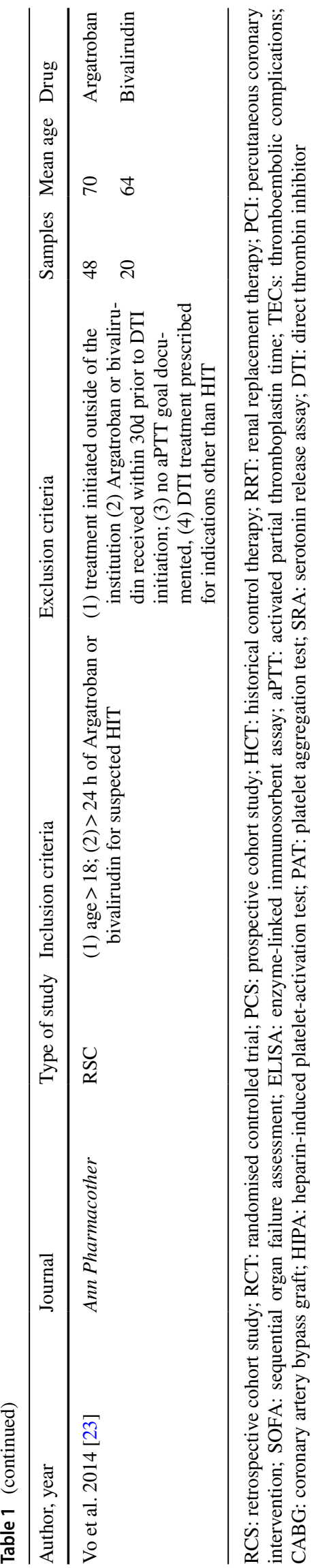

While many options for anticoagulant therapy are available, the present study focused on the effects of parenteral anticoagulation. Further analyses concerning the effects of direct oral anticoagulants and vitamin $\mathrm{K}$ antagonists for HIT are required. Lastly, fondaparinux is a synthetic heparin polysaccharide, [58] which has not been considered in this study. Given the lack of quantitative data, fondaparinux was not included in the network comparisons. Considering these limitations, data from the present Bayesian network metaanalysis must be interpreted with caution. 

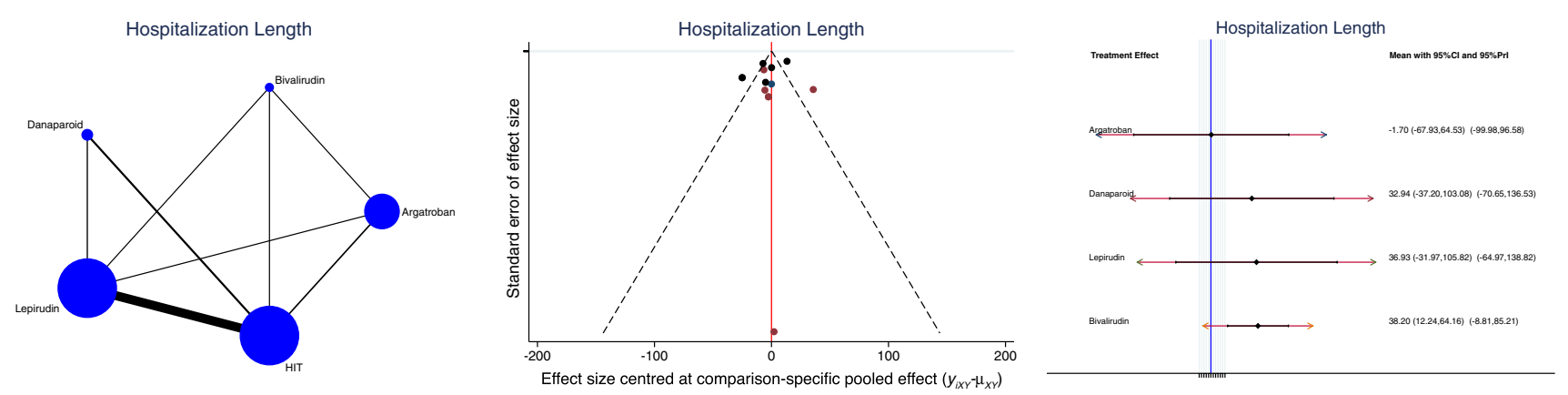

Fig. 3 Edge, funnel, and interval plots of the network comparison: hospitalization length
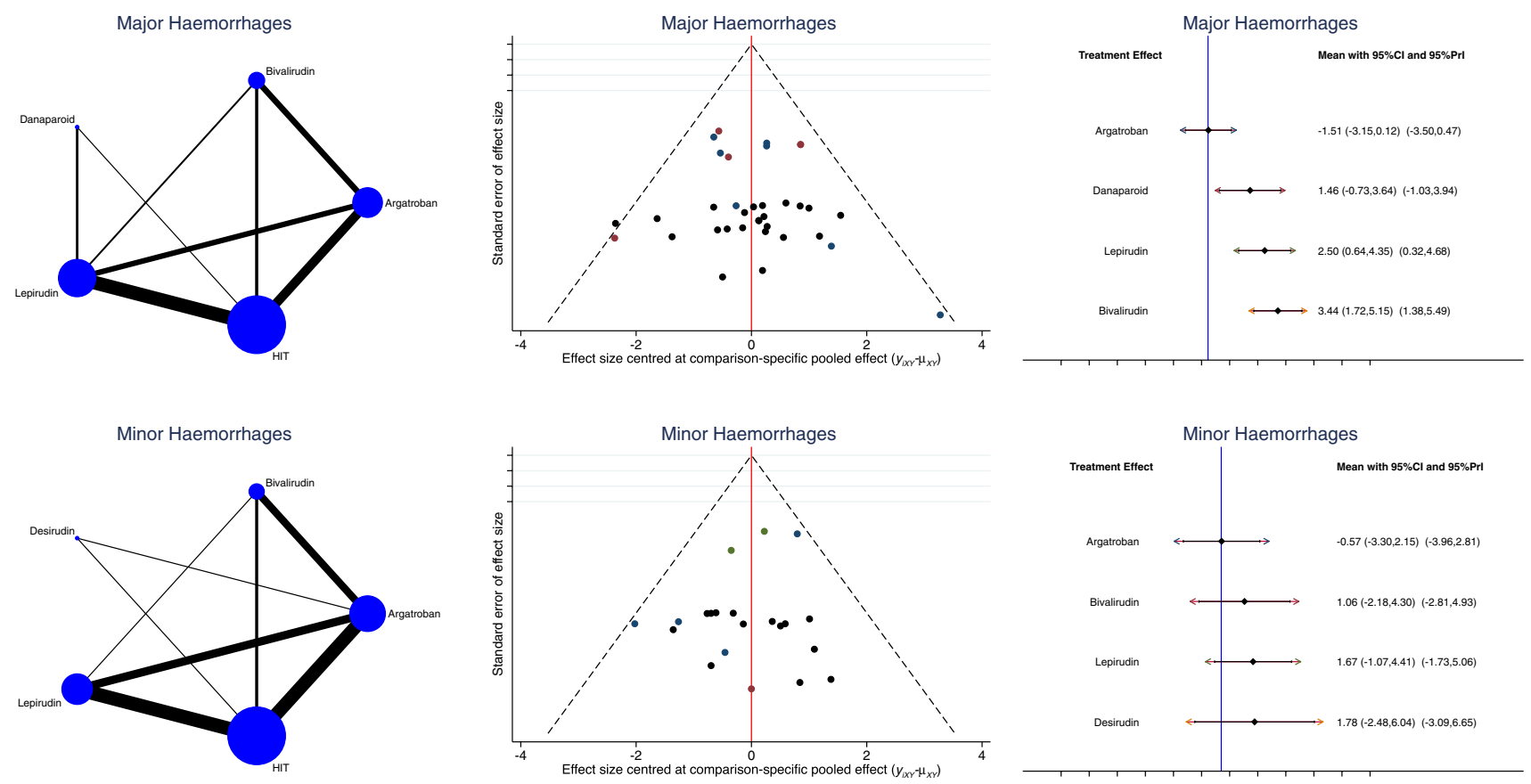

Fig. 4 Edge, funnel, and interval plots of the network comparisons: major and minor haemorrhagic events
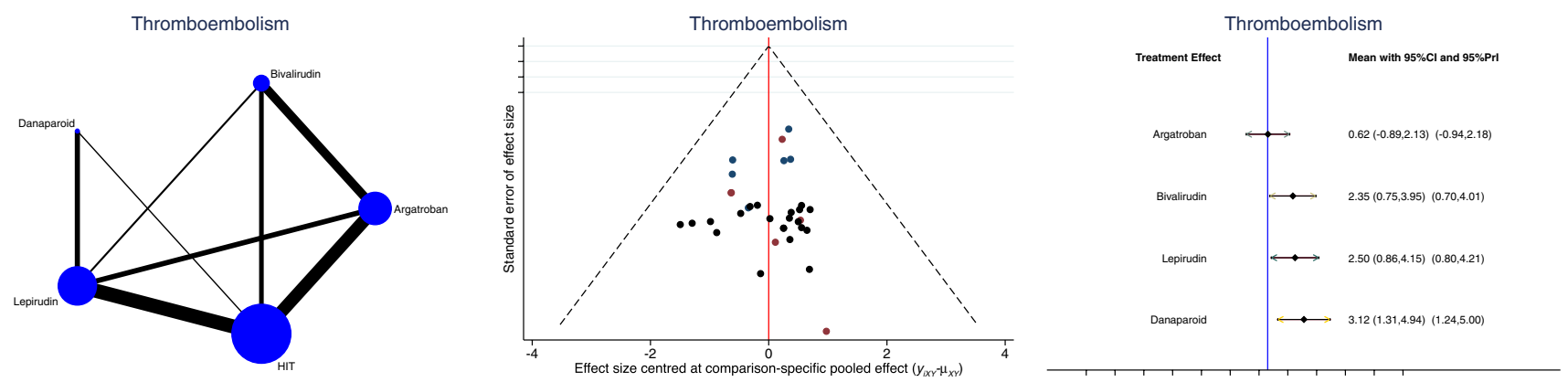

Fig. 5 Edge, funnel, and interval plots of the network comparison: thromboembolic events 

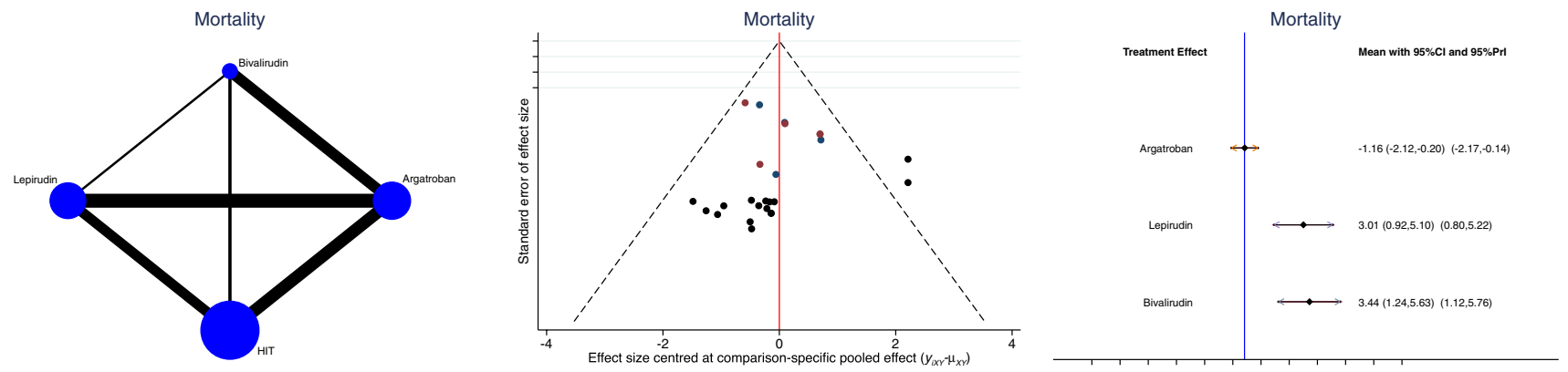

Fig. 6 Edge, funnel, and interval plots of the network comparison: mortality rate

\section{Conclusion}

Argatroban performed better overall for selected patients with HIT. Argatroban demonstrated the shortest hospitalization, and lowest rate of haemorrhages, thromboembolisms, and mortality compared to bivalirudin, lepirudin, desirudin, and danaparoid.

\section{Declarations}

Filippo Migliorini and Giorgia Colarossi performed the literature search. Nicola Maffulli and Andromahi Trivellas performed revision and approved the final version. Heike Schnöring, Nima Hatam, and Markus Tingart supervised the research and approved the final version. Filippo Migliorini performed the statistical analyses.

Funding Open Access funding enabled and organized by Projekt DEAL.. No external source of funding was used.

Conflict of interest The authors declare that they have no conflicts of interest.

Open Access This article is licensed under a Creative Commons Attribution 4.0 International License, which permits use, sharing, adaptation, distribution and reproduction in any medium or format, as long as you give appropriate credit to the original author(s) and the source, provide a link to the Creative Commons licence, and indicate if changes were made. The images or other third party material in this article are included in the article's Creative Commons licence, unless indicated otherwise in a credit line to the material. If material is not included in the article's Creative Commons licence and your intended use is not permitted by statutory regulation or exceeds the permitted use, you will need to obtain permission directly from the copyright holder. To view a copy of this licence, visit http://creativecommons.org/licenses/by/4.0/.

\section{References}

1. Greinacher A. Clinical practice heparin-induced thrombocytopenia. N Engl J Med. 2015;373(3):252-61. https://doi.org/10.1056/ NEJMcp1411910.

2. Hogan M, Berger JS. Heparin-induced thrombocytopenia (HIT): Review of incidence, diagnosis, and management. Vasc Med. 2020;25(2):160-73. https://doi.org/10.1177/1358863X19898253.

3. Dhakal B, Kreuziger LB, Rein L, Kleman A, Fraser R, Aster RH, et al. Disease burden, complication rates, and health-care costs of heparin-induced thrombocytopenia in the USA: a populationbased study. Lancet Haematol. 2018;5(5):e220-31. https://doi.org/ 10.1016/S2352-3026(18)30046-2.

4. Hirsh J, Heddle N, Kelton JG. Treatment of heparin-induced thrombocytopenia: a critical review. Arch Intern Med. 2004;164(4):361-9. https://doi.org/10.1001/archinte.164.4.361.

5. Warkentin TE, Kelton JG. Temporal aspects of heparin-induced thrombocytopenia. N Engl J Med. 2001;344(17):1286-92. https:// doi.org/10.1056/NEJM200104263441704.

6. Dager WE, White RH. Treatment of heparin-induced thrombocytopenia. Ann Pharmacother. 2002;36(3):489-503. https://doi.org/ 10.1345/aph.1A204.

7. Warkentin TE, Cook RJ, Marder VJ, Sheppard JA, Moore JC, Eriksson BI, et al. Anti-platelet factor 4/heparin antibodies in orthopedic surgery patients receiving antithrombotic prophylaxis with fondaparinux or enoxaparin. Blood. 2005;106(12):3791-6. https://doi.org/10.1182/blood-2005-05-1938.

8. Frazer CA. Heparin-induced thrombocytopenia. J Infus Nurs. 2017;40(2):98-100. https://doi.org/10.1097/NAN.0000000000 000215.

9. Prince M, Wenham T. Heparin-induced thrombocytopaenia. Postgrad Med J. 2018;94(1114):453-7. https://doi.org/10.1136/postg radmedj-2018-135702.

10. Warkentin TE, Greinacher A, Koster A, Lincoff AM. Treatment and prevention of heparin-induced thrombocytopenia: American College of Chest Physicians Evidence-Based Clinical Practice Guidelines (8th Edition). Chest. 2008;133(6 Suppl):340-80. https://doi.org/10.1378/chest.08-0677.

11. Linkins LA, Dans AL, Moores LK, Bona R, Davidson BL, Schulman S, et al. Treatment and prevention of heparin-induced thrombocytopenia: Antithrombotic Therapy and Prevention of Thrombosis, 9th ed: American College of Chest Physicians Evidence-Based Clinical Practice Guidelines. Chest. 2012;141(2 Suppl):e495S-e530S. https://doi.org/10.1378/chest.11-2303.

12. Hogan M, Berger JS. Heparin-induced thrombocytopenia (HIT): Review of incidence, diagnosis, and management. Vasc Med. 2020. https://doi.org/10.1177/1358863X19898253.

13. Nand S, Wong W, Yuen B, Yetter A, Schmulbach E, Gross FS. Heparin-induced thrombocytopenia with thrombosis: 
incidence, analysis of risk factors, and clinical outcomes in 108 consecutive patients treated at a single institution. Am J Hematol. 1997;56(1):12-6. https://doi.org/10.1002/(sici)10968652(199709)56:1\%3c12::aid-ajh3\%3e3.0.co;2-5.

14. Seybert AL, Coons JC, Zerumsky K. Treatment of heparininduced thrombocytopenia: is there a role for bivalirudin? Pharmacotherapy. 2006;26(2):229-41. https://doi.org/10.1592/phco. 26.2.229.

15. Seybert AL, Coons JC. Treatment of heparin-induced thrombocytopenia: is there a role for bivalirudin? Pharmacotherapy. 2006;26:229-41. https://doi.org/10.1592/phco.26.2.229.

16. Papadopoulos S, Flynn JD, Lewis DA. Fondaparinux as a treatment option for heparin-induced thrombocytopenia. Pharmacotherapy. 2007;27(6):921-6. https://doi.org/10.1592/phco.27.6.921.

17. Shorr AF, Eriksson BI, Jaffer AK, Smith J. Impact of stage 3B chronic kidney disease on thrombosis and bleeding outcomes after orthopedic surgery in patients treated with desirudin or enoxaparin: insights from a randomized trial. J Thromb Haemost. 2012;10(8):1515-20. https://doi.org/10.1111/j.1538-7836.2012. 04803.x.

18. Salazar CA, Malaga G, Malasquez G. Direct thrombin inhibitors versus vitamin $\mathrm{K}$ antagonists or low molecular weight heparins for prevention of venous thromboembolism following total hip or knee replacement. Cochrane Database Syst Rev. 2010. https://doi. org/10.1002/14651858.CD005981.pub2.

19. Trujillo TC. Emerging anticoagulants for venous thromboembolism prevention. Am J Health Syst Pharm. 2010;67(10 Suppl 6):S17-25. https://doi.org/10.2146/ajhp100178.

20. Dulicek P, Ivanova E, Kostal M, Fiedlerova Z, Sadilek P, Hirmerova J. Heparin-induced thrombocytopenia treated with fondaparinux: single center experience. Int Angiol. 2020;39(1):7681. https://doi.org/10.23736/S0392-9590.19.04247-0.

21. Castelino RL, Maddula M, Tarafdar S, Sud K, Kairaitis L. Danaparoid use for haemodialysis in a morbidly obese patient with heparin-induced thrombocytopenia - Need for a higher than recommended weight-based dosing. Thromb Res. 2019;180:70-3. https://doi.org/10.1016/j.thromres.2019.06.008.

22. Cuker A, Arepally GM, Chong BH, Cines DB, Greinacher A, Gruel Y, et al. American Society of Hematology 2018 guidelines for management of venous thromboembolism: heparin-induced thrombocytopenia. Blood Adv. 2018;2(22):3360-92. https://doi. org/10.1182/bloodadvances.2018024489.

23. Vo QA, Lin JK, Tong LM. Efficacy and safety of argatroban and bivalirudine in patients with suspected heparin-induced thrombocytopenia. Ann Pharmacother. 2015;49(2):178-84. https://doi.org/ 10.1177/1060028014562949.

24. Reddy BV, Grossman EJ, Trevino SA, Hursting MJ, Murray PT. Argatroban anticoagulation in patients with heparin-induced thrombocytopenia requiring renal replacement therapy. Ann Pharmacother. 2005;39(10):1601-5. https://doi.org/10.1345/aph. $1 \mathrm{G} 033$.

25. Kiser TH, Mann AM, Trujillo TC, Hassell KL. Evaluation of empiric versus nomogram-based direct thrombin inhibitor management in patients with suspected heparin-induced thrombocytopenia. Am J Hematol. 2011;86(3):267-72. https://doi.org/10. 1002/ajh.21955.

26. Duewell BE, Briski MJ, Feih JT, Rinka JRG, Tawil JN. Argatroban versus Bivalirudin in the treatment of suspected or confirmed heparin-induced thrombocytopenia. J Pharm Pract. 2019. https://doi.org/10.1177/0897190019882866.

27. Lubenow N, Eichler P, Lietz T, Farner B, Greinacher A. Lepirudin for prophylaxis of thrombosis in patients with acute isolated heparin-induced thrombocytopenia: an analysis of 3 prospective studies. Blood. 2004;104(10):3072-7. https://doi.org/10.1182/ blood-2004-02-0621.
28. Bain J, Meyer A. Comparison of bivalirudin to lepirudin and argatroban in patients with heparin-induced thrombocytopenia. Am J Health Syst Pharm. 2015;72(17 Suppl 2):S104-9. https://doi.org/ 10.2146/sp150018.

29. Beiderlinden M, Treschan TA, Gorlinger K, Peters J. Argatroban anticoagulation in critically ill patients. Ann Pharmacother. 2007;41(5):749-54. https://doi.org/10.1345/aph.1H569.

30. Greinacher A, Janssens U, Berg G, Bock M, Kwasny H, KemkesMatthes B, et al. Lepirudin (recombinant hirudin) for parenteral anticoagulation in patients with heparin-induced thrombocytopenia Heparin-Associated Thrombocytopenia Study (HAT) investigators. Circulation. 1999;100(6):587-93. https://doi.org/10.1161/ 01.cir.100.6.587.

31. Matthai WH Jr, Hursting MJ, Lewis BE, Kelton JG. Argatroban anticoagulation in patients with a history of heparin-induced thrombocytopenia. Thromb Res. 2005;116(2):121-6. https://doi. org/10.1016/j.thromres.2004.11.006.

32. Gray A, Wallis DE, Hursting MJ, Katz E, Lewis BE. Argatroban therapy for heparin-induced thrombocytopenia in acutely ill patients. Clin Appl Thromb Hemost. 2007;13(4):353-61. https:// doi.org/10.1177/1076029607303617.

33. Doepker B, Mount KL, Ryder LJ, Gerlach AT, Murphy CV, Philips GS. Bleeding risk factors associated with argatroban therapy in the critically ill. J Thromb Thrombolysis. 2012;34(4):4918. https://doi.org/10.1007/s11239-012-0758-y.

34. Frame JN, Rice L, Bartholomew JR, Whelton A. Rationale and design of the PREVENT-HIT study: a randomized, open-label pilot study to compare desirudin and argatroban in patients with suspected heparin-induced thrombocytopenia with or without thrombosis. Clin Ther. 2010;32(4):626-36. https://doi.org/10. 1016/j.clinthera.2010.04.012.

35. Boyce SW, Bandyk DF, Bartholomew JR, Frame JN, Rice L. A randomized, open-label pilot study comparing desirudin and argatroban in patients with suspected heparin-induced thrombocytopenia with or without thrombosis: PREVENT-HIT Study. Am J Ther. 2011;18(1):14-22. https://doi.org/10.1097/MJT.0b013e3181 f65503.

36. Iqbal O, Tobu M, Aziz S, Gerdisch M, Da Valle M, Demir M, et al. Successful use of recombinant hirudin and its monitoring by ecarin clotting time in patients with heparin-induced thrombocytopenia undergoing off-pump coronary artery revascularization. J Card Surg. 2005;20(1):42-51. https://doi.org/10.1111/j.08860440.2005.200316.x.

37. Skrupky LP, Smith JR, Deal EN, Arnold H, Hollands JM, Martinez EJ, et al. Comparison of bivalirudin and argatroban for the management of heparin-induced thrombocytopenia. Pharmacotherapy. 2010;30(12):1229-38. https://doi.org/10.1592/phco.30. 12.1229.

38. Dang CH, Durkalski VL, Nappi JM. Evaluation of treatment with direct thrombin inhibitors in patients with heparin-induced thrombocytopenia. Pharmacotherapy. 2006;26(4):461-8. https://doi.org/ 10.1592/phco.26.4.461.

39. Lewis BE, Wallis DE, Berkowitz SD, Matthai WH, Fareed J, Walenga JM, et al. Argatroban anticoagulant therapy in patients with heparin-induced thrombocytopenia. Circulation. 2001;103(14):1838-43. https://doi.org/10.1161/01.cir.103.14. 1838.

40. Fischer KG, van de Loo JB. Recombinant hirudin (lepirudin) as anticoagulant in intensive care patients treated with continuous hemodialysis. Kidney Int. 1999;56(72):46-50.

41. Hutton B, Salanti G, Caldwell DM, Chaimani A, Schmid CH, Cameron $\mathrm{C}$, et al. The PRISMA extension statement for reporting of systematic reviews incorporating network meta-analyses of health care interventions: checklist and explanations. Ann Intern Med. 2015;162(11):777-84. https://doi.org/10.7326/M14-2385. 
42. Howick J CI, Glasziou P, Greenhalgh T, Heneghan C, Liberati A, Moschetti I, Phillips B, Thornton H, Goddard O, Hodgkinson M. The 2011 Oxford Levels of Evidence. Oxford Centre for Evidence-Based Medicine Available at http://www.cebm.net/index. aspx?o=5653. (2011).

43. Greinacher A, Eichler P, Lubenow N, Kwasny H, Luz M. Heparininduced thrombocytopenia with thromboembolic complications: meta-analysis of 2 prospective trials to assess the value of parenteral treatment with lepirudin and its therapeutic aPTT range. Blood. 2000;96(3):846-51.

44. Grouzi E. Update on argatroban for the prophylaxis and treatment of heparin-induced thrombocytopenia type II. J Blood Med. 2014;5:131-41. https://doi.org/10.2147/JBM.S38762.

45. Warkentin TE, Kelton JG. A 14-year study of heparin-induced thrombocytopenia. Am J Med. 1996;101(5):502-7. https://doi.org/ 10.1016/s0002-9343(96)00258-6.

46. Sedhai YR, Mahat KC, Krishnan P. Argatroban. StatPearls. Treasure Island (FL), (2020).

47. Gruel Y, De Maistre E, Pouplard C, Mullier F, Susen S, Roullet $\mathrm{S}$, et al. Diagnosis and management of heparin-induced thrombocytopenia. Anaesth Crit Care Pain Med. 2020. https://doi.org/ 10.1016/j.accpm.2020.03.012.

48. Dou H, Song A, Jia S, Zhang L. Heparinoids Danaparoid and Sulodexide as clinically used drugs. Prog Mol Biol Transl Sci. 2019;163:55-74. https://doi.org/10.1016/bs.pmbts.2019.02.005.

49. Warkentin TE. Bivalent direct thrombin inhibitors: hirudin and bivalirudin. Best Pract Res Clin Haematol. 2004;17(1):105-25. https://doi.org/10.1016/j.beha.2004.02.002.

50. Greinacher A, Lubenow N, Eichler P. Anaphylactic and anaphylactoid reactions associated with lepirudin in patients with heparin-induced thrombocytopenia. Circulation. 2003;108(17):2062-5. https://doi.org/10.1161/01.CIR.00000 96056.37269.14.

51. Tschudi M, Lammle B, Alberio L. Dosing lepirudin in patients with heparin-induced thrombocytopenia and normal or impaired renal function: a single-center experience with 68 patients. Blood. 2009;113(11):2402-9. https://doi.org/10.1182/ blood-2008-07-162271.

52. Treschan TA, Schaefer MS, Geib J, Bahlmann A, Brezina T, Werner P, et al. Argatroban versus Lepirudin in critically ill patients (ALicia): a randomized controlled trial. Crit Care. 2014;18(5):588. https://doi.org/10.1186/s13054-014-0588-8.

53. Farner B, Eichler P, Kroll H, Greinacher A. A comparison of danaparoid and lepirudin in heparin-induced thrombocytopenia. Thromb Haemost. 2001;85(6):950-7.

54. Ljajikj E, Zittermann A, Morshuis M, Borgermann J, Ruiz-Cano $\mathrm{M}$, Schoenbrodt M, et al. Bivalirudin anticoagulation for left ventricular assist device implantation on an extracorporeal life support system in patients with heparin-induced thrombocytopenia antibodies. Interact Cardiovasc Thorac Surg. 2017;25(6):898-904. https://doi.org/10.1093/icvts/ivx251.

55. Warkentin TE, Koster A. Bivalirudin: a review. Expert Opin Pharmacother. 2005;6(8):1349-71. https://doi.org/10.1517/14656 566.6.8.1349.

56. Sun Z, Lan X, Li S, Zhao H, Tang Z, Xi Y. Comparisons of argatroban to lepirudin and bivalirudin in the treatment of heparininduced thrombocytopenia: a systematic review and meta-analysis. Int J Hematol. 2017;106(4):476-83. https://doi.org/10.1007/ s12185-017-2271-8.

57. Barlow A, Barlow B, Reinaker T, Harris J. Potential role of direct oral anticoagulants in the management of heparin-induced thrombocytopenia. Pharmacotherapy. 2019;39(8):837-53. https:// doi.org/10.1002/phar.2298.

58. Zhang Y, Zhang M, Tan L, Pan N, Zhang L. The clinical use of Fondaparinux: a synthetic heparin pentasaccharide. Prog Mol Biol Transl Sci. 2019;163:41-53. https://doi.org/10.1016/bs.pmbts. 2019.02.004.

59. Abel EE, Kane-Gill SL, Seybert AL, Kellum JA. Direct thrombin inhibitors for management of heparin-induced thrombocytopenia in patients receiving renal replacement therapy: comparison of clinical outcomes. Am J Health Syst Pharm. 2012;69(18):1559_ 67. https://doi.org/10.2146/ajhp110540.

60. Bartholomew JR, Pietrangeli CE, Hursting MJ. Argatroban anticoagulation for heparin-induced thrombocytopenia in elderly patients. Drugs Aging. 2007;24(6):489-99. https://doi.org/10. 2165/00002512-200724060-00005.

61. Beiderlinden M, Werner P, Bahlmann A, Kemper J, Brezina T, Schafer M, et al. Monitoring of argatroban and lepirudin anticoagulation in critically ill patients by conventional laboratory parameters and rotational thromboelastometry-a prospectively controlled randomized double-blind clinical trial. BMC Anesthesiol. 2018;18(1):18. https://doi.org/10.1186/s12871-018-0475-y.

62. Curzio KM, Cheng-Lai A, Kheyfets V, Sinnet M, Billett HH. A comparison of direct thrombin inhibitors in the treatment of Heparin-induced thrombocytopenia: a single institution experience. J Thromb Thrombolysis. 2009;28(2):117-23. https://doi.org/10. 1007/s11239-008-0275-1.

63. Dyke CM, Aldea G, Koster A, Smedira N, Avery E, Aronson $\mathrm{S}$, et al. Off-pump coronary artery bypass with bivalirudin for patients with heparin-induced thrombocytopenia or antiplatelet factor four/heparin antibodies. Ann Thorac Surg. 2007;84(3):8369. https://doi.org/10.1016/j.athoracsur.2007.04.007.

64. Greinacher A, Volpel H, Janssens U, Hach-Wunderle V, Kemkes-Matthes B, Eichler P, et al. Recombinant hirudin (lepirudin) provides safe and effective anticoagulation in patients with heparin-induced thrombocytopenia: a prospective study. Circulation. 1999;99(1):73-80. https://doi.org/10.1161/01.cir.99.1.73.

65. Koster A, Dyke CM, Aldea G, Smedira NG, McCarthy HL 2nd, Aronson S, et al. Bivalirudin during cardiopulmonary bypass in patients with previous or acute heparin-induced thrombocytopenia and heparin antibodies: results of the CHOOSE-ON trial. Ann Thorac Surg. 2007;83(2):572-7. https://doi.org/10.1016/j.athor acsur.2006.09.038.

66. Lewis BE, Wallis DE, Leya F, Hursting MJ, Kelton JG, Argatroban I. Argatroban anticoagulation in patients with heparininduced thrombocytopenia. Arch Int Med. 2003;163(15):1849-56. https://doi.org/10.1001/archinte.163.15.1849.

67. Lubenow N, Eichler P, Lietz T, Greinacher A, Hit IG. Lepirudin in patients with heparin-induced thrombocytopenia - results of the third prospective study (HAT-3) and a combined analysis of HAT1, HAT-2, and HAT-3. J Thromb Haemost. 2005;3(11):2428-36. https://doi.org/10.1111/j.1538-7836.2005.01623.x.

68. Smythe MA, Stephens JL, Koerber JM, Mattson JC. A comparison of lepirudin and argatroban outcomes. Clin Appl Thromb Hemost. 2005;11(4):371-4. https://doi.org/10.1177/107602960501100403.

69. Tardy-Poncet B, Nguyen P, Thiranos JC, Morange PE, BironAndreani C, Gruel Y, et al. Argatroban in the management of heparin-induced thrombocytopenia: a multicenter clinical trial. Crit Care. 2015;19:396. https://doi.org/10.1186/s13054-015-1109-0.

Publisher's Note Springer Nature remains neutral with regard to jurisdictional claims in published maps and institutional affiliations. 